\title{
Numerical and Experimental Analysis to Study the Effect of Double Triangle Core on the Dynamic Response of Sandwich Structure
}

\author{
Safaa Mohammed Hwalah ${ }^{a}$, Hatem Hadi Obeid ${ }^{a^{*}}$, Essam Zuheir Fadhel ${ }^{\text {a }}$ \\ ${ }^{a}$ Department of mechanical engineering, University of Babylon, Babil, Iraq
}

\author{
ARTICLE INFO \\ Article history: \\ Received 03 January 2020 \\ Accepted 28 February 2020

Keywords:
Corrugated cores
Impact Load
Honeycomb cores
Transient analysis
Sandwich structure
sandwich composite \\ Keywords: \\ Corrugated cores \\ Impact Load \\ Transient analysis \\ sandwich composite
}

Received in revised form 19 February 2019

\begin{abstract}
A B S T R A C T
Sandwich structure plates are most widely used in the automotive, aerospace and naval structures. As it gives material with low density and relatively high normal compression and shear properties. In this paper, Finite element method was used with ANSYS APDL (16) to analyze the effect of duplicate core in sandwich steel structure on the dynamic response under the action of impact loading. Also, conducted impact tests with hammer and NI devises to achieve the simulation results. The chief purpose of this work is to get a high reduction in deformation between upper and lower skins. Isolate deflections of sandwich plates are compared between single and double cores of structures. The construction of the sandwich composite model consisted of two sheets layers with single triangle corrugated core and three sheets layer with double triangle corrugated core. All of configurations for both core and skin are made from the same material (steel alloy 304$)$ and have $(500 \mathrm{~mm} \times 500 \mathrm{~mm}$ ) length and width. The results observed that the reduction of deflection and strain are increased in double core. The comparison between experimental and numerical transient results gives good agreement with error does not exceed (13\%).
\end{abstract}

(C) 2020 University of Al-Qadisiyah. All rights reserved.

\section{Introduction}

The base design of sandwich involves two thin faces that are connected by a thick cellular core. The bonding among core and two faces allows the faces and core to act as a single structure, producing a high lighter weight and strong structure [1]. Showed by analytical, numerical and experimentally tests that the sandwich composite beam had a more flexural stiffness if compared with core and skin stiffness as thicknesses increase. Energy of laminate indentation was less than sandwich energy but sandwich indentation consumes further energy.
Experimental results were in good agreement with the analytical and numerical analyses [2]. Studied the dynamic response of stainless-steel square honeycomb sandwich structure, by carried out explosive experimental test in air at three values of impact load. Tests were done on the sandwich structure and solid plates at constant weight. At the lowest load, it indicated that the significant front face bending and cell wall buckled gradually in the centre near to the explosion [3]. Presented experimental study and numerical analysis about the compressive

* Corresponding author.

E-mail address: drhatemhadi@yahoo.com (Hatem Hadi) 


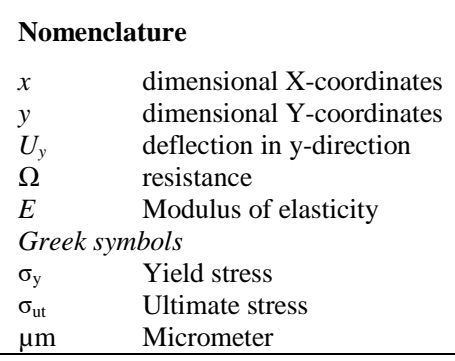

dynamic behaviour of four corrugated sandwich plates, these corrugated cores are (V-core, U-core, X- core and Y-core). Showed that the first three core type sandwich structures had better performance than the (Y-core) type in the cracking behaviour and energy absorption characteristic, and when it was corrugated to ( $\mathrm{N}$-core) type the characteristic of crushing and energy absorption would been dramatically enhancing [4]. Aimed to configure a new design of corrugated sandwich structures made from glass fibre and carbon fibre were capable of energy absorption by experimental tests. It was concluded that mixing face sheet of glass and carbon fibres (half to half) was able to provide the equivalent specific bending strength as the face sheets made fully of carbon fibre. Also, indicated that the increasing the inclined angle and the thickness of core and sheet led to enhancement the strength [5]. Comparison study had been achieved by using finite elements, design of experiment with response surface methods among triangular and trapezoidal corrugated sandwich structures. The results demonstrated that at constant face thickness and core high, the core cell shape did not play a largely role on the low velocity local impact response, but it's had obviously affected on the planar impact response. Also, it was found that the crash resistance of triangular type was slightly better than the trapezoidal type [6]. Proved that the deformation and crash level of sandwich trapezoidal core made of steel was increased with decreased impact load source distance and the thickness of front face played an important role on the deformation if compared with back face. So, a high deformation occurred in the front face and a lower deformation of back face were obtained when the increased of core height. Also, observed that when the core height increased a high deformation would obtain at the front face and a lower deformation of back face [7]. Investigated experimentally by using (DIC) method the dynamic behaviour of sandwich with metallic face skins and (PVC) foam core under blast loading and fully clamped. It is showed that low density thick core could extended responding time and good energy absorption ability, but when using high density thin core showed its capable absorption energy when subjected to strong impulse [8]. Conducted experimental tests on honeycomb sandwich structure with aluminium skins to study the effects of filler material on the failure mode. It could be found that there was an increased in the elastic strength of the sandwich structure when insert the polyurethane foam. The energy absorbed of foam filled sandwich structure was $24 \%$ more than unfilled structure [9].

From the above literature, it found that a few researchers deal with the effect of double corrugated cores on the response of sandwich structure. Therefore, in this paper, it will be studying the effects of adding second core on the energy absorption and deformation mode, which gives stiffer structure and mine deflection reduction between upper and lower skins. This analysis will be done numerically by using ANSYS APDL (16) and experimentally impact with NI devises.

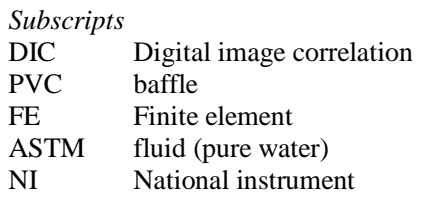

\section{Finite Element Modelling}

ANSYS (APDL16.0) software solver is used for numerical analysis in this paper, are powerful analysis tools include pre-processing (configuration of models, meshing formulation), solver and postprocessing tools in a graphical user interface. The main objectives of the numerical analysis are simulating the experimental tests that configured the sandwich structure and obtain the difference in the dynamic response was carried out experimentally. For all calculations, conditions at an initial time are set to be zero, while boundary condition is clamped from left and right edges (all degree of freedoms is taken as zero) and free from other sides. A vertical concentrated impact load is subjected at the center of upper face sheet of the models.

\subsection{Element Types}

ANSYS offers a large packages of different element types that can be used with various problems simulation. The selection of suitable element is a significant matter in the analysis procedure. Good knowledge and experience of the application are to be studied and finite element theory will support the selection of suitable type.

Every element type in (ANSYS) has a particular number and prefix which specify the type of group such as Solid, Link, Shell, Beam, and so on. Each element type determines among other structural members as:

1. The degree of freedoms (DOF) adjustment (that involved the structural, thermal, magnetic, electric, bricks, etc.)

2. The specification of the element coordinates, which are 2-D or 3-D domain.

The analysis of the current study requires two types of elements to create the correct model: (SHELL281) element for sandwich structure. This element type contains (8 nodes) with (6 DOF), translations and rotations in three directions.

\section{Configuration and Material Properties of Models}

Single and double triangle corrugated core were configured the sandwich structure with layers of face sheets. The sandwich model with single core has a mass of $(11.2 \mathrm{~kg})$ and $(18.4 \mathrm{~kg})$ in double core, with five-unit cell in the corrugation of the cores. The model and its dimension with single core are shown in Figs. 1.a and 1.b, while the model with double cores is shown in Figs. 2.a and 2. b. The thickness of skin is $(1 \mathrm{~mm})$ and core is $(2 \mathrm{~mm})$, while the depth is $(500 \mathrm{~mm})$. All dimensions in $(\mathrm{mm})$. The properties of materials are isotropic and have an elastic modulus (198 Gpa), density $\left(7835 \mathrm{~kg} / \mathrm{m}^{3}\right)$.

The materials of core and skin are chosen low carbon steel with carbon percent $(0.25 \%-0.29 \%)$. The mechanical properties such as ultimate 
stress, yield stress, modulus of elasticity and the elongation were obtained from tensile test of grade A36, while poisson ratio ( was taken from standard ASTM A36 Low Carbon Steel as (0.3). Six samples (3 samples with $2 \mathrm{~mm}$ thickness and 3 others with $1 \mathrm{~mm}$ thickness), these samples shown in Fig. 3. Sheet type of ASTM A370 was adopted in the experimental test methods and definitions of steel products.

The environmental temperature at the laboratory test was $25^{\circ} \mathrm{C}$ and moisture was $40 \%$. The rate of sample displacement is $(2 \mathrm{~mm} / \mathrm{min}$.). The results that obtained was the average of six specimens are shown in Table 1.

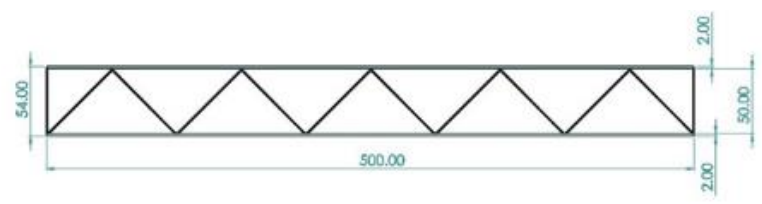

Figure 1.a. Dimensions of sandwich plate with single triangle corrugated core.
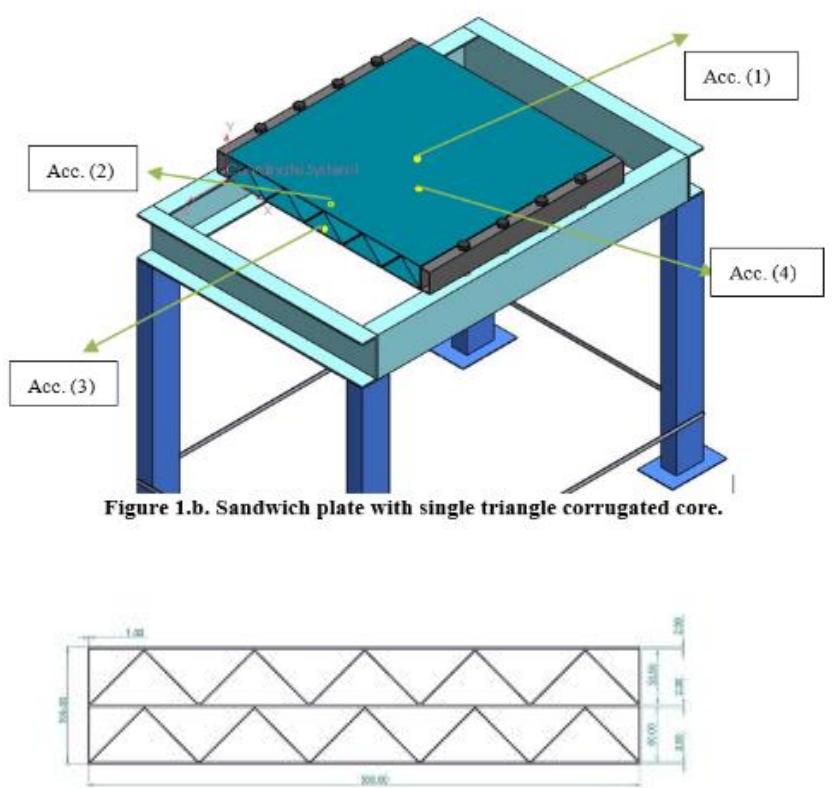

Figure 2.a. Dimenstous of saudwieh plate with donble triaugle corrugated core.

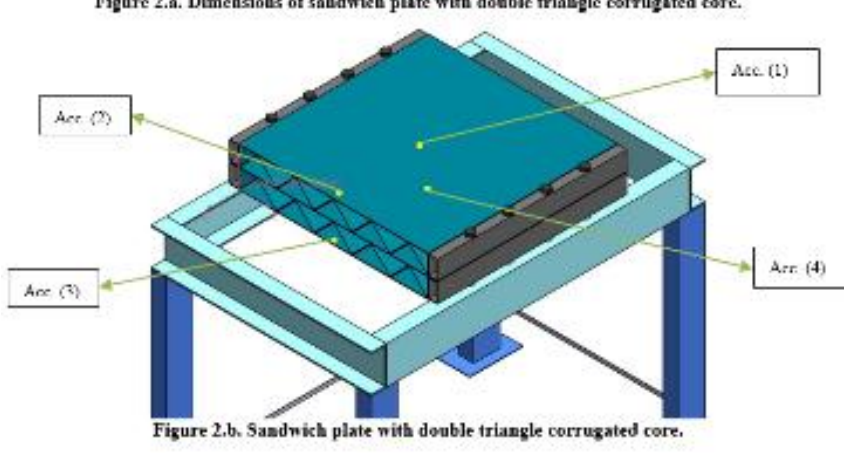

\section{Experimental Analysis Test of Sandwich Structure Plate}

The experimental analysis test includes transient analysis studying strain and transient time response. Multi experimental tests were done to get better results. The sensors that are used in the analysis are strain gauges and accelerometers. The experimental test involves parts that illustrate in the following sections:

\subsection{Accelerometer sensors}

Four piezotronics (352C03) model type accelerometers fixed in the skins of sandwich structure to sense the acceleration. The properties, number and location of these accelerometers shown in Table 2.

At first cleaned the surface of the interest points that the accelerometer which fixed on it and put adhesive fluid then fixed the accelerometer with carefully as shown in Fig. 4.

Table 1. The results of tensile test.

\begin{tabular}{llll}
\hline Parameter & Symbol & Value & Unit \\
\hline Yield stress & $\sigma_{\mathrm{y}}$ & 225 & $\mathrm{MPa}$ \\
Ultimate stress & $\sigma_{\mathrm{ut}}$ & 318 & $\mathrm{MPa}$ \\
Modulus of elasticity & $\mathrm{E}$ & 198 & $\mathrm{GPa}$ \\
Elongation & $\Delta \mathrm{L}$ & $23 \%$ & --- \\
\hline
\end{tabular}

Table 2. Accelerometer properties and information.

\begin{tabular}{cccccc}
\hline \multirow{2}{*}{ Structure } & $\begin{array}{c}\text { Accelerometer } \\
\text { number }\end{array}$ & \multicolumn{3}{c}{ Coordinate $(\mathbf{m})$} & \multirow{2}{*}{ Sensitivity } \\
\cline { 2 - 5 } Single & 1 & $\mathbf{x}$ & $\mathbf{y}$ & $\mathbf{z}$ & \\
\hline \multirow{2}{*}{ core } & 2 & 0.25 & 0.05 & -0.2 & 10.31 \\
& 3 & 0.25 & 0.05 & -0.05 & 9.93 \\
& 4 & 0.25 & 0 & -0.05 & 10.24 \\
Double & 1 & 0.25 & 0.1 & -0.2 & 9.95 \\
core & 2 & 0.25 & 0.1 & -0.05 & 10.31 \\
& 3 & 0.25 & 0 & -0.05 & 10.24 \\
& 4 & 0.25 & 0 & -0.2 & 9.95 \\
\hline
\end{tabular}

\subsection{Strain gauge sensors}

The test of strain involves two strain gauges in each test, one was joined in the upper skin and other in the lower skin. The fixation method was done carefully as below.

1.Refinement and cleaning the skins until the surface is very smooth and clean.

2.Added strong adhesive on the place of strain gauge then put the strain gauge on the adhesive and pressed it until full adhesion.

3.Wiring connection of strain gauge was done by lead solder welding as shown in Fig. 5.

This fixation makes the strain gauge combined with the structure, so any strain in the structure will be transferred to strain gauges. The model type of these strain gauges is (BE120-20AA-X-4cm lead wire) that have resistance of $120 \pm 0.1(\Omega)$ and gauge factor was (2.00-2.20) while the number and location of these strain gauges shown in Table3.

Table 3. properties of strain gauges.

\begin{tabular}{ccccc}
\hline \multirow{2}{*}{ Structure } & \multirow{2}{*}{ Strain gauge number } & \multicolumn{3}{c}{ Coordinate $(\mathbf{m})$} \\
\cline { 3 - 5 } & & $\mathbf{x}$ & $\mathbf{y}$ & $\mathbf{z}$ \\
\hline Single & 1 & 0.2 & 0.05 & -0.25 \\
core & 2 & 0.2 & 0 & -0.25 \\
\hline Double & 1 & 0.2 & 0.1 & -0.25 \\
core & 2 & 0.2 & 0 & -0.25 \\
\hline
\end{tabular}

\subsection{Impact hammer}

Piezotronics (086C03) impact hammer is the type that is used for the structure in the current work for exciting an impulse force for transient test. This hammer consists of quartz force sensor fixed in the end of the hammer head as shown in Fig. 6. Impulse testing involves striking the model with the impact hammer at the center point of upper face, and measuring the resultant motion with an accelerometers that are fixed at an interest locations [10]. 


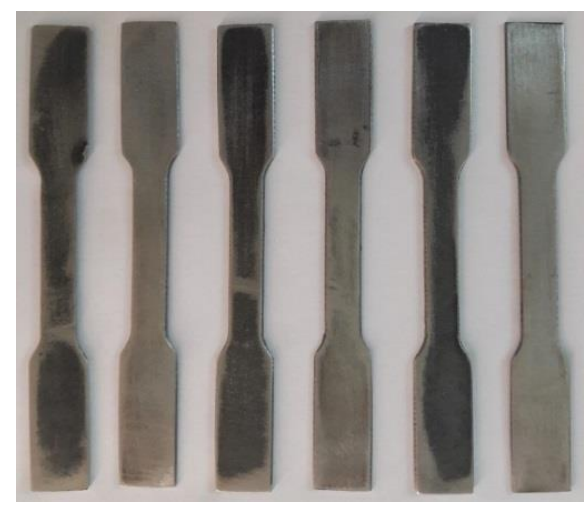

Figure 3. Tensile test samples.

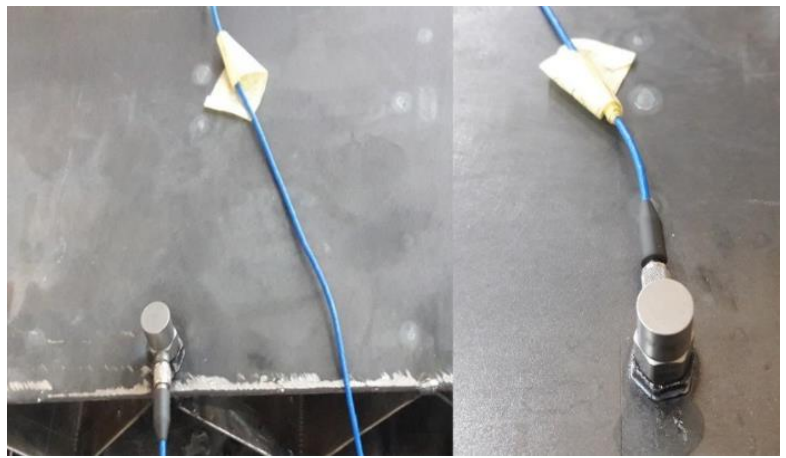

Figure 4. Piezotronics accelerometers that fixed on the upper skin.

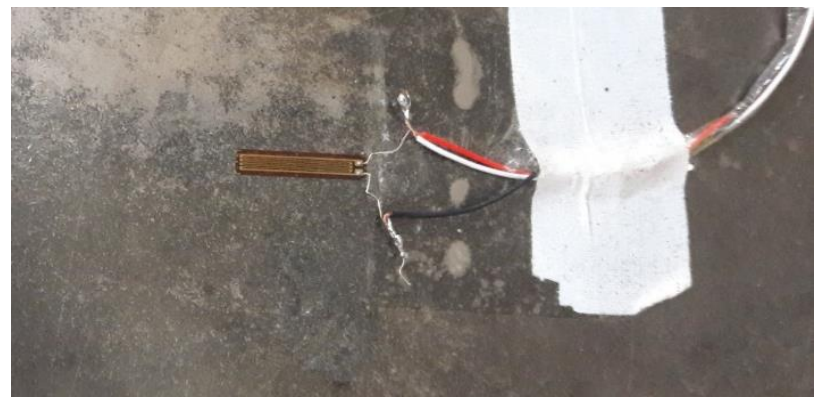

Figure 5. Strain gauge that are fixed in the upper skin.

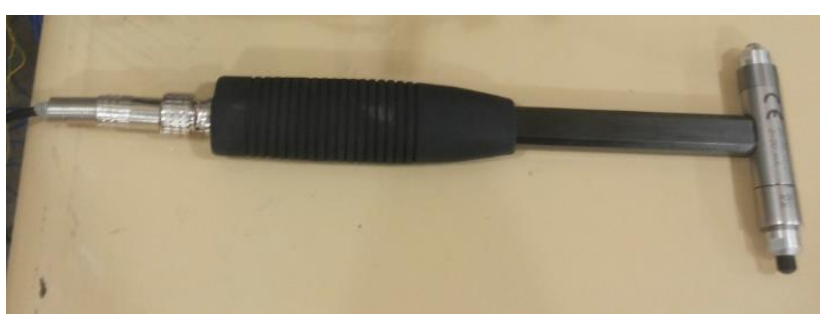

Figure 6. Impact hammer instrument.

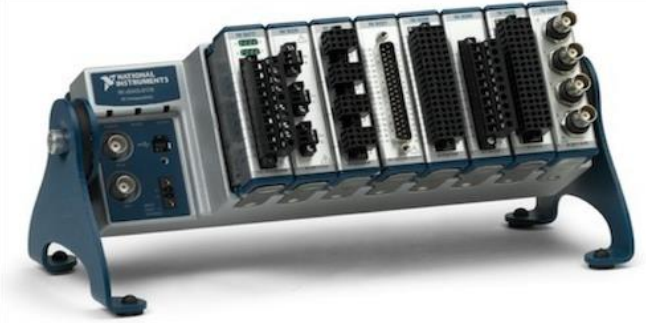

Figure 7. NI compact DAQ chassis [11].

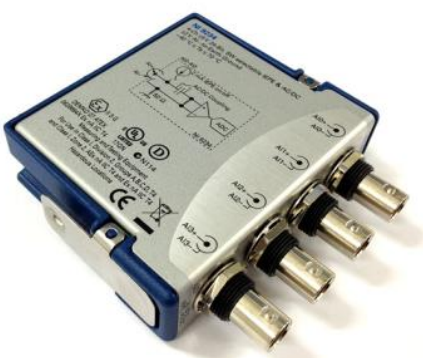

Figure 8. NI 9234 module [12].

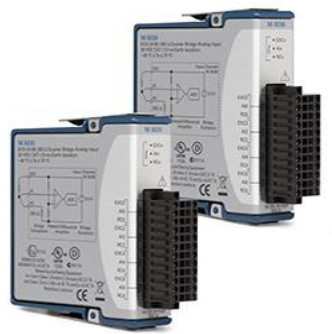

Figure 9. NI 9235 module [13].

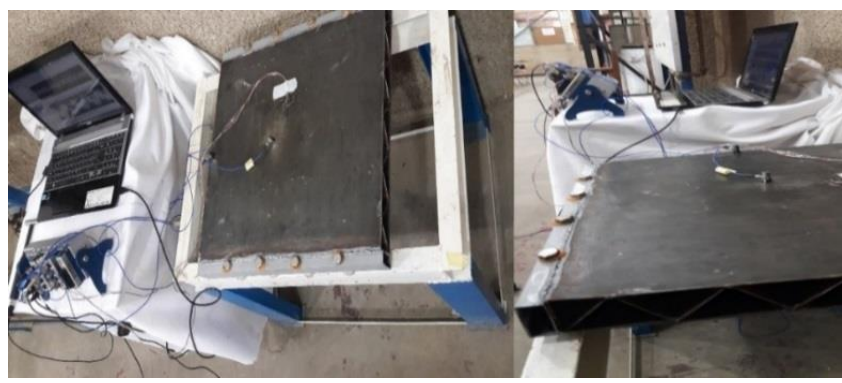

Figure 10.a. Rig and vibration test of single core steel sandwich plate.

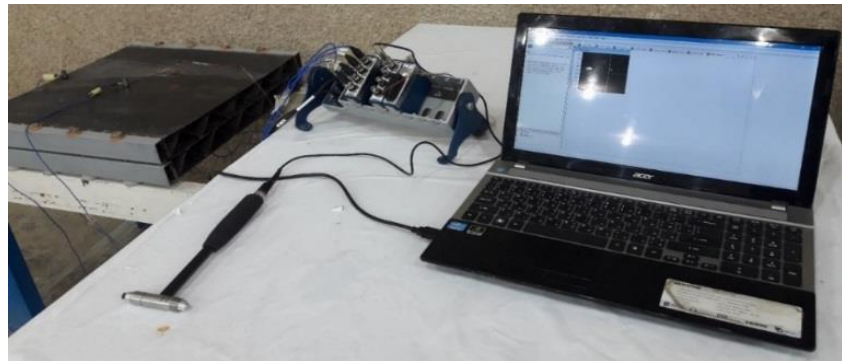

Figure 10.b. Rig and vibration test of double core steel sandwich plate. 


\subsection{NI compact DAQ (USB Data Acquisition Systems)}

The NI instruments is the main equipment used in the experimental test, one of them is the chassis 9178-DAQ that have an eight channel and designed for small and mixed-measurement test systems as shown in Fig. 7. The 9178-DAQ contains four 32-bit for counter/timers compact, these counters can access through an installed, hardwaretimed digital module [11].

\subsubsection{NI 9234 and NI 9235 modules}

The module (9234) has four channel for receiving dynamic signal from sensors such as accelerometer (as in the test) and transfer it to chassis 9178-DAQ to making high-accuracy measurements. Fig. 8 shows this module [12]. NI 9235 quarter-bridge strain gauge modules shown in Fig. 9 is designed for higher-channel-count, dynamic strain measurement systems for NI Compact DAQ or Compact RIO [13].

These devices are collected together during the tests and reading signals were extracted from the sensors by using (sound and vibration program). A real photo of the assembly of all parts of experimental test and devices shown in Figs. 10.a and 10.b.

\section{Results}

The experimental tests results include the response of the sandwich structures were manufactured with single and double triangle cores and compared with corresponding simulation results. The impact load applied in the upper face sheet has value of $(200 \mathrm{~N})$ during $(0.01 \mathrm{~ms})$ for single and double core structures that was conducted by a hammer. The results obtained are the deflection in $(\mathrm{Y})$ direction and strain in $(\mathrm{X})$ direction. The tests were achieved by using stainless steel tip hammer.

\subsection{Results of Single Core Sandwich Structure}

To obtain the deflection and strain responses, the pulse was subjected by the hammer in the test and numerically by ANSYS as shown in Fig. 11.

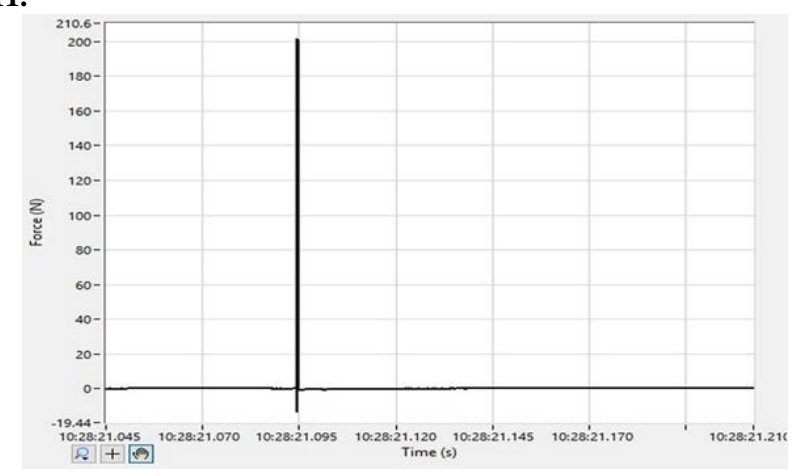

Figure 11. Magnitude of force applied.

\subsubsection{Results of deflection in y-direction}

Fig. 12 shows the results of deflection that obtained from accelerometers after integrated the signal by sound and vibration software. The maximum deflection in this model occurred in the experimental results at (point 1$)$ with $(0.266 \mu \mathrm{m})$ and in simulation results with $(0.249 \mu \mathrm{m})$. The error between experimental and numerical simulation was $6.83 \%$ in (point 1 ) and $4.33 \%$ in (point 4 ).

\subsubsection{Results of strain in in $x$-direction}

The strain results as shown in Fig. $\mathbf{1 3}$ are obtained from the strain gauge sensors. It is clear that the maximum strain occurred in the experimental results at (point 1$)$ is $(0.32 \mu \mathrm{m} / \mathrm{m})$ and in the simulation results is $(0.36 \mu \mathrm{m} / \mathrm{m})$. The error between experimental and numerical simulation was $11.60 \%$ in (point 1 ) and $8.64 \%$ in (point 2).

\subsection{Results of Double Core Sandwich Structure}

To obtain the deflection and strain responses, the same pulse was subjected by the hammer in the test and numerically by ANSYS.

\subsubsection{Results of strain in in $x$-direction}

The strain result that shown in the Fig. 14 indicate that behavior is the same as in the single core structure, and there is no difference in the value of strain between single and double core in the (point 1 ). While the value of strain in the (point 2) that located in the lower face was reduced by percentage about (60\%) compared with the single core. The maximum strain occurred in the experimental results at (point 1) is $(0.34 \mu \mathrm{m} / \mathrm{m})$ and in simulation results is $(0.37 \mu \mathrm{m} / \mathrm{m})$. The error between experimental and numerical simulation was $8.11 \%$ in (point 1) and $2.15 \%$ in (point 2).

\subsubsection{Results of deflection in y-direction}

The deflection of the double core is shown in Fig. 15 indicate that the maximum deflection occurred in the experimental results at (point 1) with $(0.23 \mu \mathrm{m})$ and in simulation results with $(0.24 \mu \mathrm{m})$. From the response figures it is find that the double core structure differs from single core in reduced the value of the (point 4 ) by (93.5\%). While the maximum deflection of the (point 1) does not change largely in the double core structure. This reduction is due to high moment of inertia in the double core, so can be absorbed high energy. The error between experimental and numerical simulation was $6.12 \%$ in (point 1) and $12.57 \%$ in (point 4 ).

\subsection{Maximum Values and Percentage of Reduction}

It is clear from the results that the double core of sandwich structure increased the reduction in deflection and strain between upper and lower faces, because the high of the structure increased and this led to increase the moment of inertia. So, the bending stress and deflection is reduced in the double core sandwich structure. But we must not forget that the weight in the double core is more than single core by $(60 \%)$, and the heavy weight structure gives high strength and more reduction, yet remains the double core is better in terms of reduction and strength. Table 4 illustrate the maximum values of deflection and the percentage of reduction in single and double cores of numerical results and Table 5 for experimental tests.

From Tables 4 and 5 the comparison between experimental and numerical results of transient load gives good agreement with maximum difference error don't exceeded (13\%). This differences are attributed to the material mechanical properties of tensile test error that used in numerical part, the noise of experimental devices error, model dimensions, bonding and contact between core and skins, boundary conditions effect and fixation of model. Also, the load point in the numerical analysis is node that has very small area while in the 
experimental test the steel tip of hammer has normally more area that subjected to the force.

Table 4. Maximum deflection and strain with reduction percentage between central points of the numerical results.

\begin{tabular}{lllll}
\multirow{2}{*}{ No. of cores } & & \multicolumn{3}{l}{ Results of ANSYS in $(\mathbf{m m})$} \\
\cline { 3 - 5 } & & Point 1 & Point 4/2 & Reduction \\
\hline \multirow{2}{*}{ Deflection } & Single Core & $2.49 \mathrm{E}-7$ & $2.31 \mathrm{E}-7$ & $7.23 \%$ \\
& Double Core & $2.45 \mathrm{E}-7$ & $1.83 \mathrm{E}-8$ & $92.53 \%$ \\
\hline \multirow{2}{*}{ Strain } & Single Core & $3.62 \mathrm{E}-7$ & $2.20 \mathrm{E}-7$ & $39.23 \%$ \\
& Double Core & $3.70 \mathrm{E}-7$ & $8.38 \mathrm{E}-8$ & $77.35 \%$ \\
\hline
\end{tabular}

Table 5. Maximum deflection and strain with reduction percentage between central points of the experimental tests.

\begin{tabular}{ccccc}
\hline \multirow{2}{*}{\multicolumn{2}{c}{ No. of cores }} & \multicolumn{3}{c}{ Results of experimental tests in (mm) } \\
\cline { 3 - 5 } & & Point 1 & Point 4/2 & Reduction \\
\hline \multirow{2}{*}{ Deflection } & Single Core & $2.66 \mathrm{E}-7$ & $2.41 \mathrm{E}-7$ & $9.40 \%$ \\
& Double Core & $2.30 \mathrm{E}-7$ & $1.60 \mathrm{E}-8$ & $93.04 \%$ \\
\hline \multirow{2}{*}{ Strain } & Single Core & $3.20 \mathrm{E}-7$ & $2.01 \mathrm{E}-7$ & $37.19 \%$ \\
& Double Core & $3.40 \mathrm{E}-7$ & $8.20 \mathrm{E}-8$ & $75.88 \%$ \\
\hline
\end{tabular}

Note: Point 4 refer to the accelerometer no. while point 2 refer to the strain gauge no.

\section{Conclusions}

The following conclusions have been obtained:

- The comparison between the single core and double core sandwich structure showed that the reduction of deflection and strain are increased in double core.

- The experimental results showed that the maximum deflection occurred at the (point 1$)$ with value of $(0.266 \mu \mathrm{m})$ in single core and $(0.230 \mu \mathrm{m})$ in double core at the same point. While the minimum deflection occurred at the (point 3 ) with value of $(3.4 \mathrm{~nm})$ in double core but, in the single core the value was $(0.75 \mathrm{~nm})$ at the (point 2$)$.

- The numerical results showed that the maximum deflection occurred at the (point 1$)$ with value of $(0.249 \mu \mathrm{m})$ in single core and $(0.245$ $\mu \mathrm{m})$ in double core at the same point. While the minimum deflection occurred at the (point 3 ) with value of $(3.3 \mathrm{~nm})$ in double core but, in the single core the value was $(0.85 \mathrm{~nm})$ at the (point 2$)$.

- The experimental results showed that the maximum strain occurred at the upper point and lower strain at the lower point.

- The high reduction in deflection and strain occurred in the double core sandwich structure.
- The increased in percentage of reduction in deflection was from (9\%) in single core to (93\%) in double core, while the weight of structure was increased by $60 \%$ only.

- The comparison between experimental and numerical transient results gives good agreement with error does not exceed (13\%).

\section{REFERENCES}

[1] D. Gay, S.V. Hoa, S. W. Tsai, Composite Materials Design and Application, second edition, CRC Press LLC, (2003).

[2] M. Sadighi, H. Pouriayevali, M. Saadati, A Study of indentation energy in three points bending of sandwich beams with composite laminated faces and foam core, World academy of science, engineering and technology international journal of physical and mathematical sciences, (1) (12) (2007) 121-127.

[3] K.P. Dharmasena, H.N.G. Wadley, Z. Xue, J.W. Hutchinson, Mechanical response of metallic honeycomb sandwich panel structures to high-intensity dynamic loading, International journal of impact engineering, (35) (2008) 1063-1074.

[4] Z. Yan-Chang, Z. Shi-lian, W. Zi-li, Crush behavior of corrugated cores sandwich panels, Advanced materials research, (217-218) (2011) 1584-1589.

[5] J. Zhang, P. Supernak, S. Mueller-Alander, C.H. Wang, Improving the bending strength and energy absorption of corrugated sandwich composite structure, Materials and design, (52) (2013) 767-773.

[6] S. Hou, S. Zhao, L. Ren, X. Han, Q. Li, Crashworthiness optimization of corrugated sandwich panels, Materials and design, (51) (2013) 1071-1084.

[7] P. Zhang, J. Liu, Y. Cheng, H. Hou, C. Wang, Y. Li, Dynamic response of metallic trapezoidal corrugated-core sandwich panels subjected to air blast loading - An experimental study, Materials and design, (65) (2014) 221-230.

[8] N. Ye, W. Zhang, D. Li, W. Huang, W. Xie, X. Huang, X. Jiang, Dynamic response and failure of sandwich plates with PVC foam core subjected to impulsive loading, International Journal of Impact Engineering, (109) (2017) 121-130.

[9] F.H. Roudbeneh, G. Liaghat, H. Sabouri, H. Hadavini, Experimental investigation of impact loading on honeycomb sandwich panels filled with foam, International Journal of Crashworthiness, (17) (2018).

[10] Model 086C03 ICP Impact Hammer Installation and Operating Manual.

[11] NI Compact-DAQ USB Data Acquisition Systems NI cDAQ-9178 chassis Installation and Operating Manual.

[12] NI 9234 module Installation and Operating Manual.

[13] NI 9235 module Installation and Operating Manual. 
Experimentally deflection of point (1)

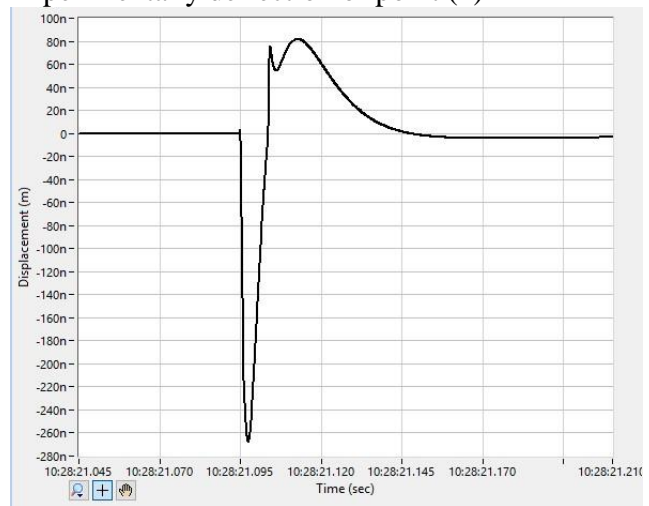

Numerically deflection of point (1)

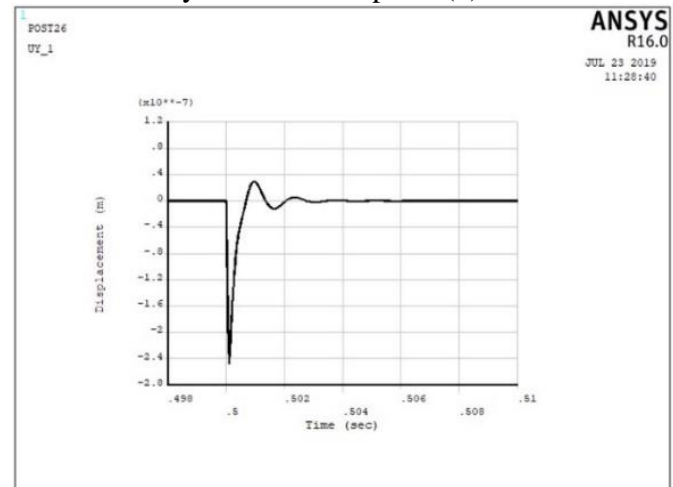

Experimentally deflection of point (3)

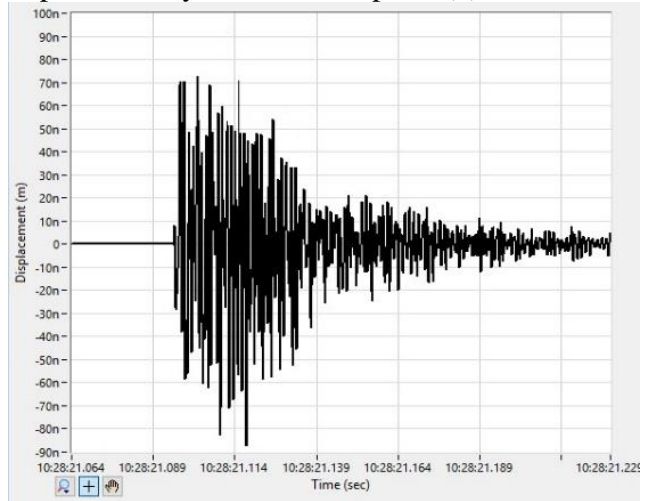

Numerically deflection of point (3)

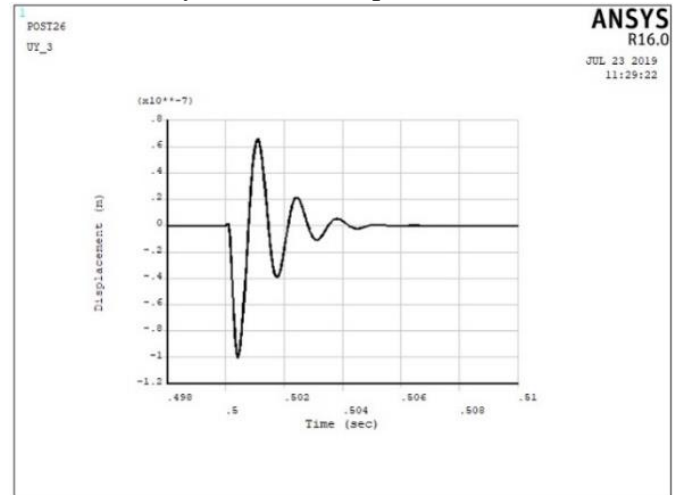

Experimentally deflection of point (2)

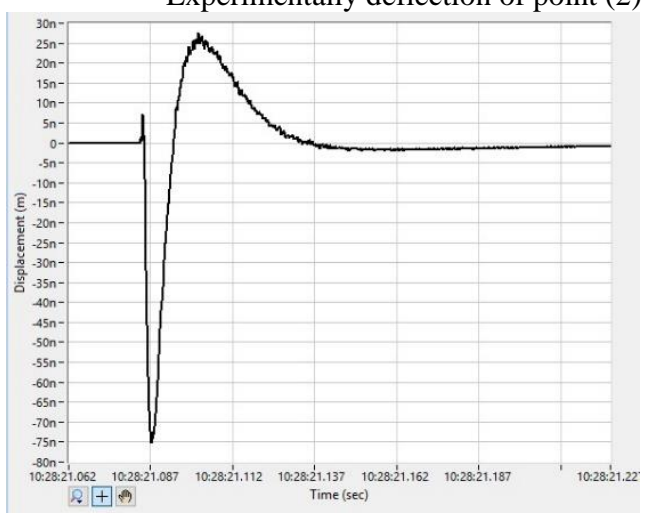

Numerically deflection of point (2)
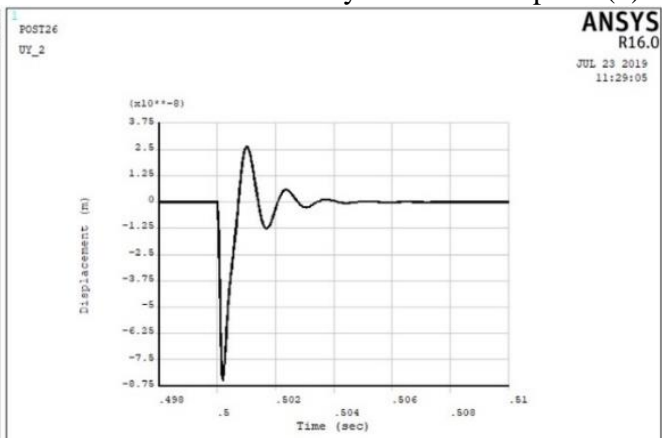

Experimentally deflection of point (4)

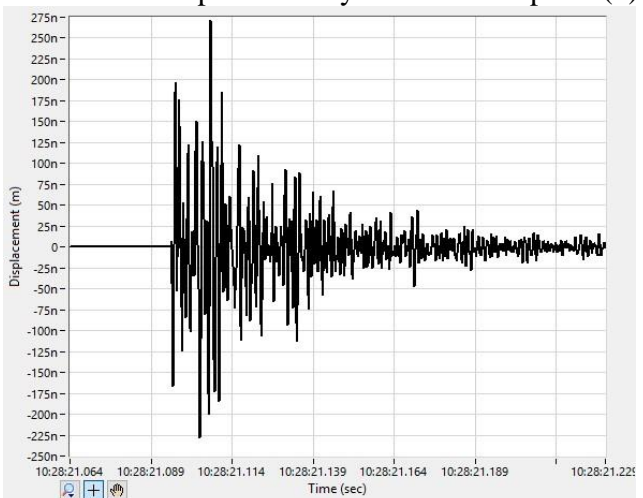

Numerically deflection of point (4)

Post26

ANSYS

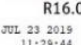

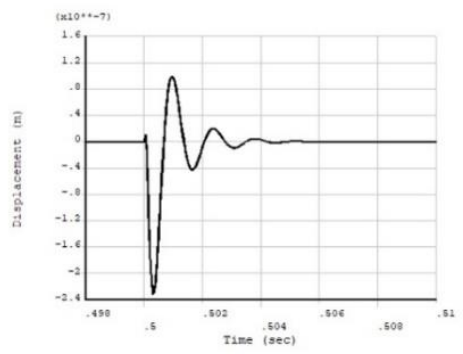

Figure 12. Experimental and numerical deflection of single core sandwich structure. 

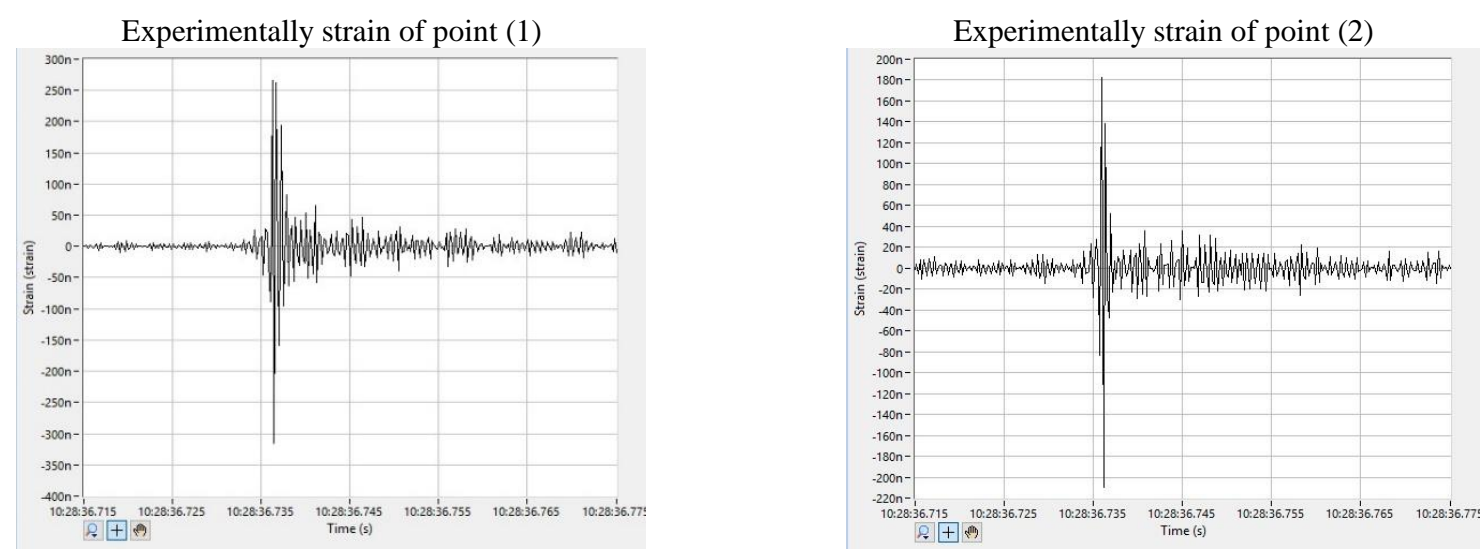

Numerically strain of point (1)

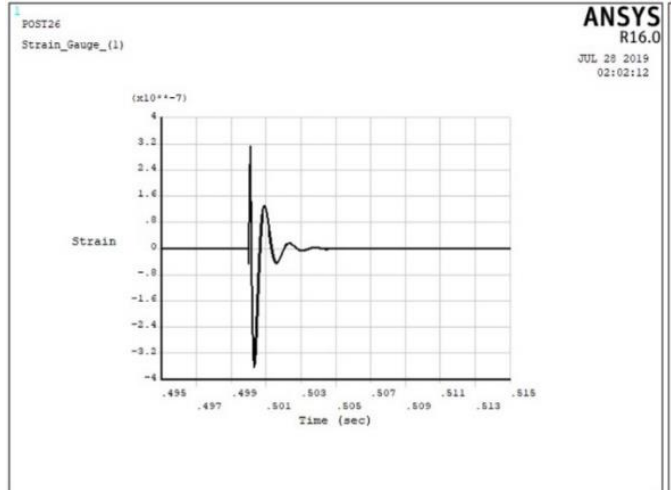

Numerically strain of point (2)

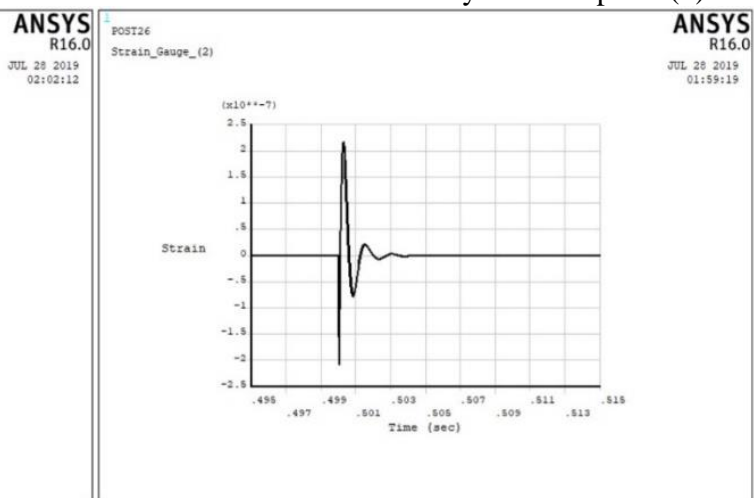

Figure 13. Experimental and numerical strain of single core sandwich structure.
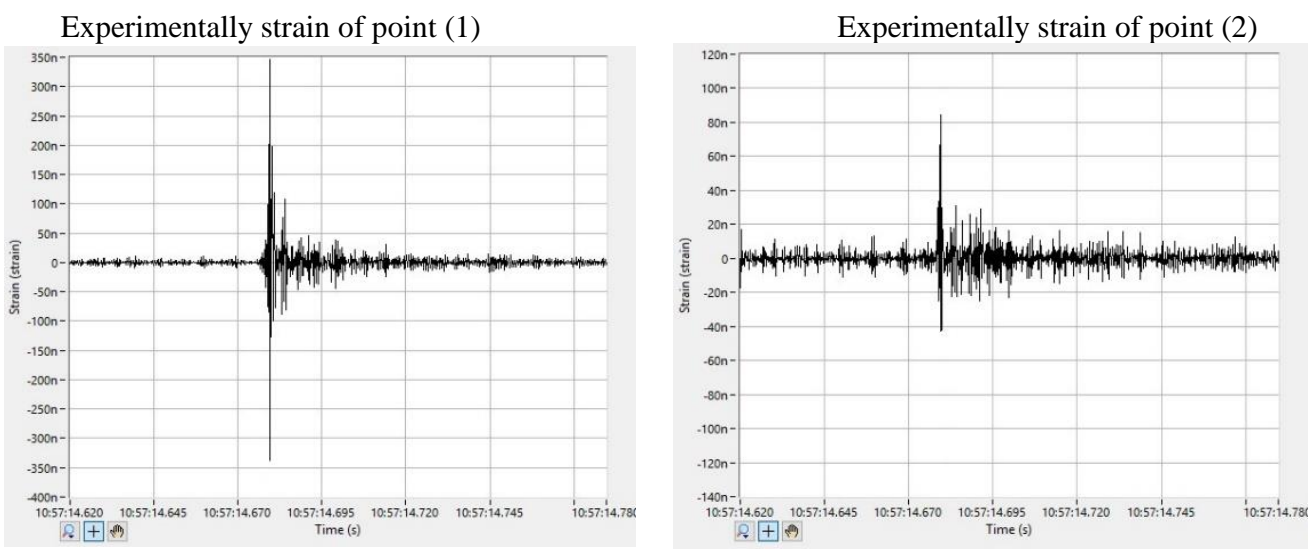

Numerically strain of point (1)
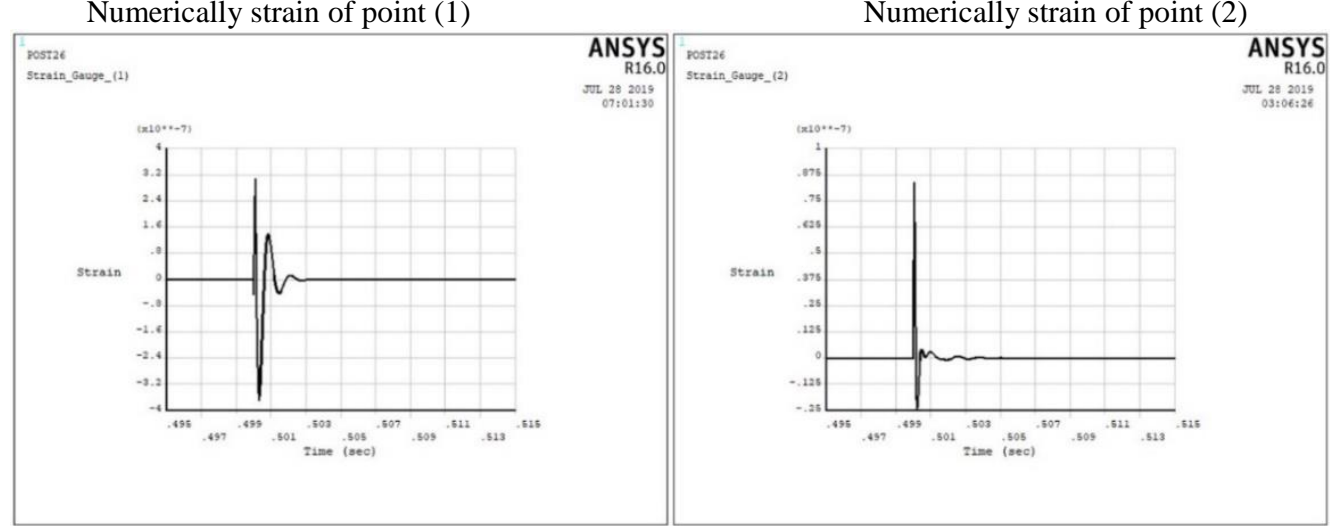

Figure 14. Experimental and numerical strain of double core sandwich structure. 
Experimentally deflection of point (1)

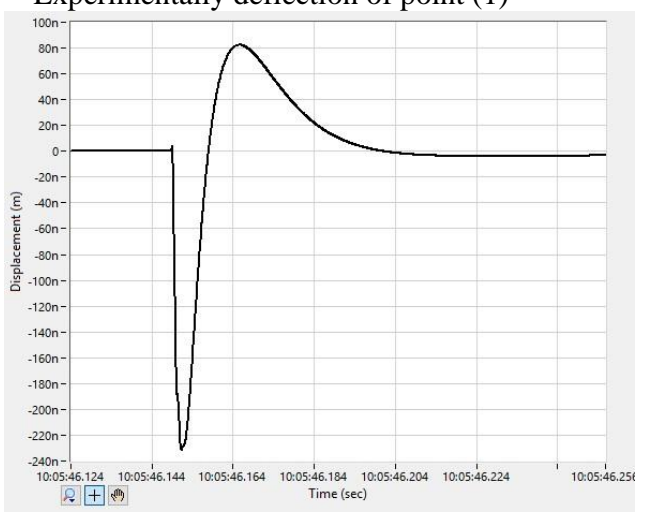

Numerically deflection of point (1)
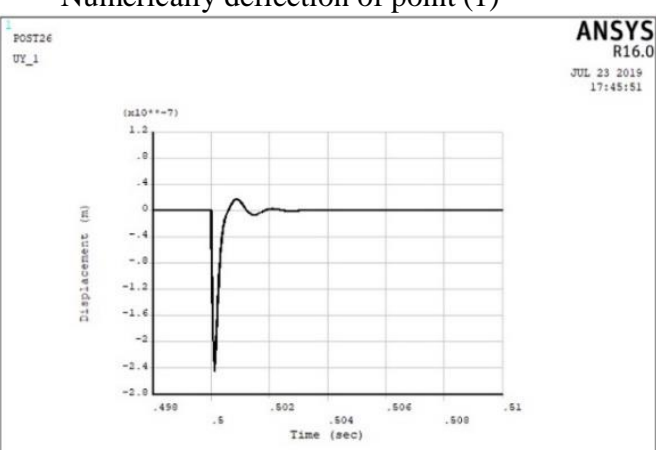

Experimentally deflection of point (3)

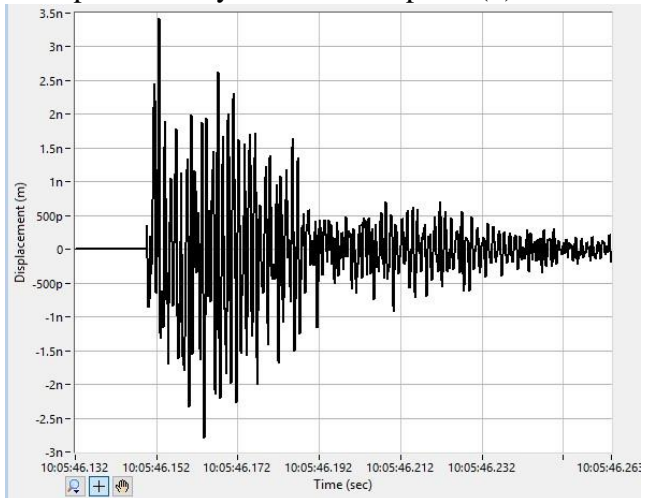

Numerically deflection of point (3)

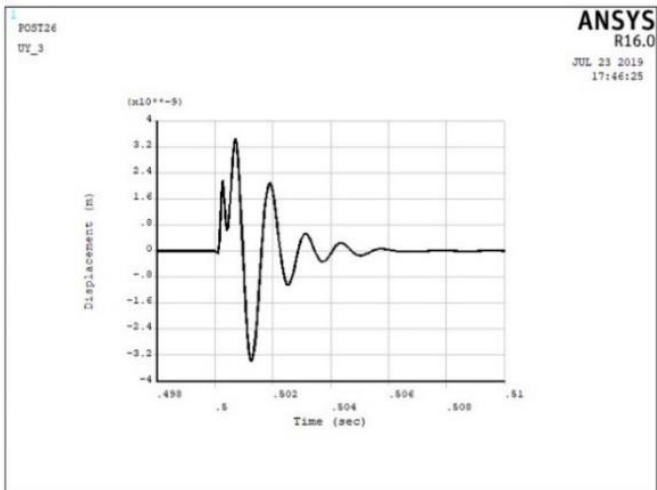

Experimentally deflection of point (2)

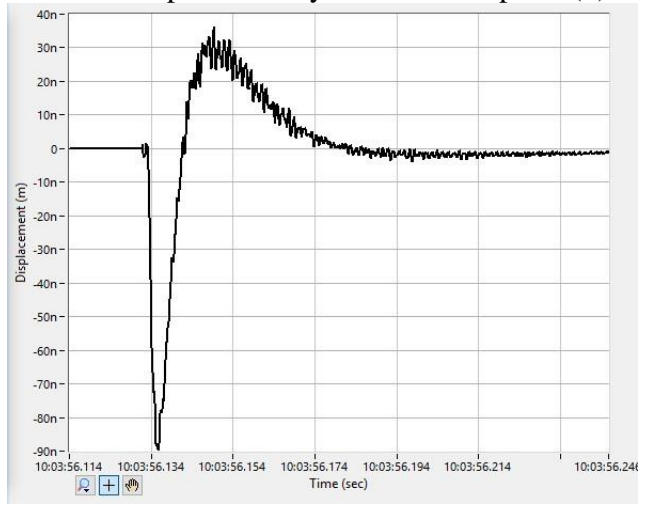

Numerically deflection of point (2)
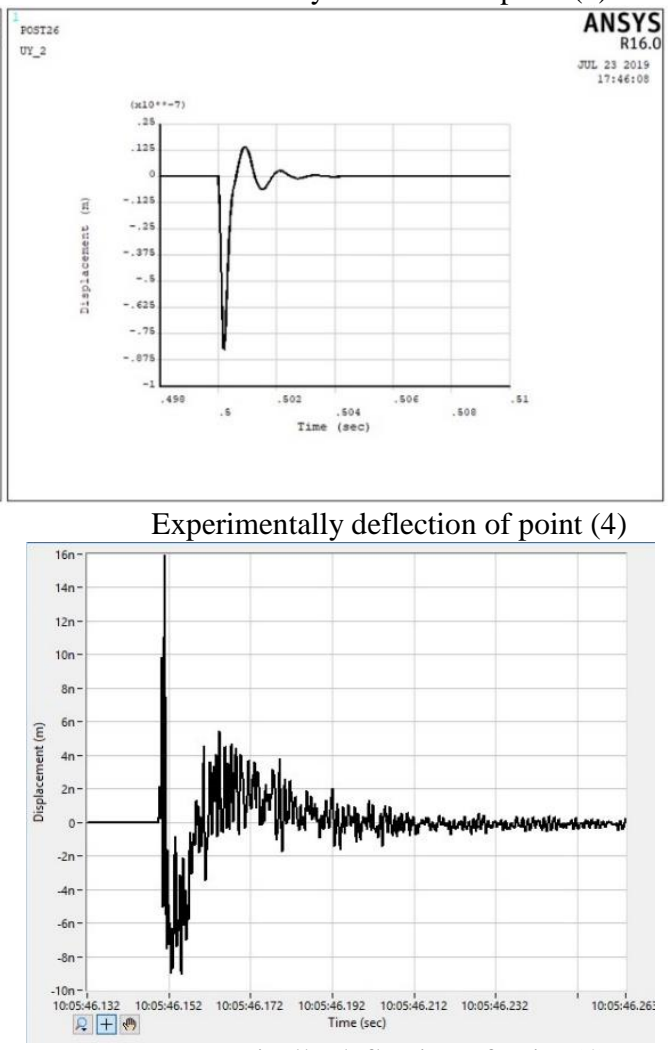

Numerically deflection of point (4)

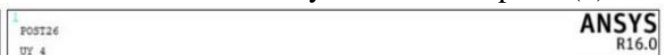

UY_-4

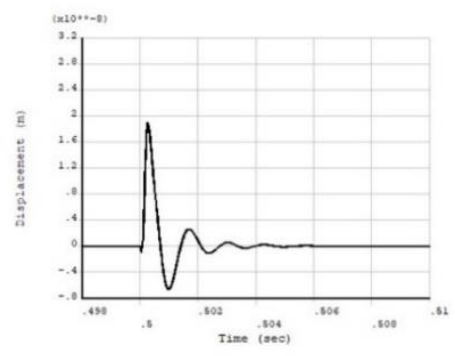

Figure 15. Experimental and numerical deflection of double core sandwich structure. 